\title{
Ureterocele - A case report
}

\author{
P. K. Chhetri ${ }^{1}$, S K Malla ${ }^{2}$ \\ ${ }^{1}$ Assistant Professor, ${ }^{2}$ Junior Resident, Department of Radiodiagnosis, College of Medical Sciences, Bharatpur, Chitwan \\ District, Nepal
}

\begin{abstract}
Congenital ureterocele is an uncommon cause of urinary tract obstruction in the young patient. Though they may be diagnosed in utero, some however present in the first few decades of life. Most are associated with a duplex collection system with complete ureteral duplication. Here we report a case of single system ureterocele associated with only a single ureter.
\end{abstract}

Key words: ureterocele, urinary tract obstruction.

\section{Introduction}

The term ureterocele was first used by Leshnew in 1912 and defines a cystic dilatation of the distal, intravesical portion of the ureter. A single system ureterocele is associated with a kidney with only one ureter, whereas a duplex system ureterocele is associated with the upper pole of a kidney with a complete ureteral duplication. Most frequently the pelvicaliceal system drained by the ureterocele is also obstructed. ${ }^{1}$

The simplest and most widely adopted classification of ureteroceles was proposed by the Committee on Terminology of the Urologic Section of the American Academy of Paediatrics. ${ }^{2}$ According to this classification, ureteroceles contained entirely within the bladder are named orthotopic or intravesical, while an ureterocele that has a portion permanently located outside of the bladder is called ectopic.

Stenotic ureteroceles are completely located inside the bladder and have a small, stenotic, often pinpoint, Correspondence: Dr. P.K. Chhetri

E-mail:pramodchhetri@rediffmail.com orifice; they are usually tense and show a well muscularized wall with predominantly longitudinal muscle fibres. The non-obstructed variety is rather rare and in such cases the ureterocele is visible only when a peristaltic wave fills it ${ }^{1}$.

\section{Case report}

A 12 year old boy was referred to the radiology department for CT scan of the abdomen with a ultrasound diagnosis of a cystic mass in the right iliac fossa and moderate right hydronephrosis. Beside some mild abdominal discomfort and occasional difficult urination he had no significant complains. His clinical examination was also unremarkable. His routine urine examination showed few pus cells.

Axial (figure 1 to 3 ) and coronal (figure 4) post contrast enhanced CT scan of the abdomen showed a cystic lesion within the urinary bladder lumen with dilated and tortuous right distal ureter associated with moderate right hydronephrosis. The contralateral kidney was normal. 
Figure 1. Axial CT scan at the level of the urinary bladder shows the ureterocele as a cystic lesion within the urinary bladder lumen.
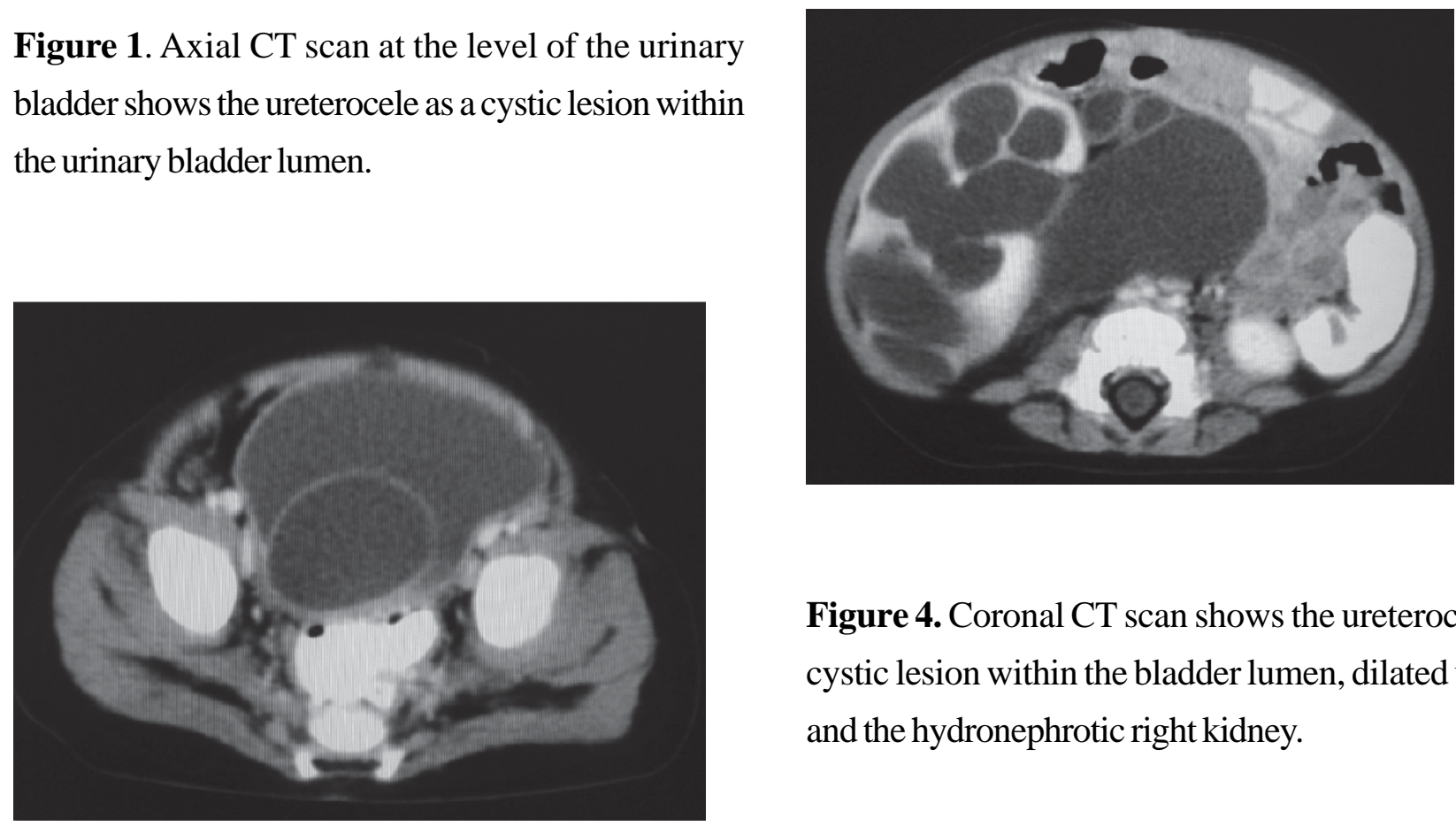

Figure 4. Coronal CT scan shows the ureterocele as cystic lesion within the bladder lumen, dilated ureter and the hydronephrotic right kidney.

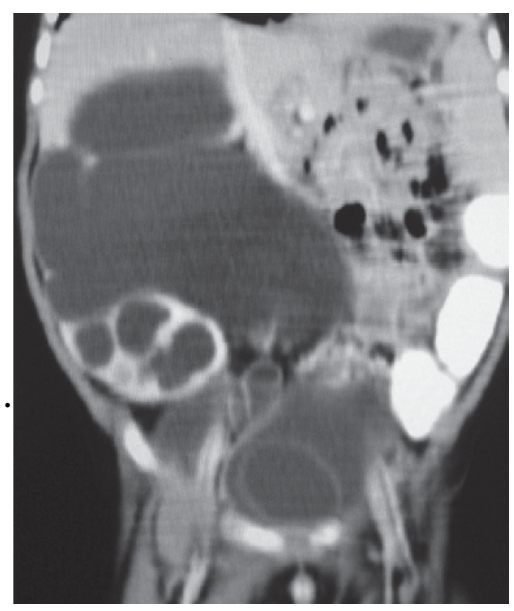

\section{Discussion}

The incidence of ureterocele varies in the literature. In a careful autopsy study, Uson ${ }^{3}$ noted a much higher incidence than was previously reported (as many as 1

Figure 3. Axial CT scan at the level of the kidney shows the dilated renal pelvis and right hydronephrosis with cortical parenchymal thinning. in 500). The malformation is observed more frequently in Caucasians than in other races and females are affected four to six times more frequently than males. ${ }^{4}$ Some $80 \%$ of ureteroceles are associated with the upper pole of a complete duplication, and in most series $60-80 \%$ are ectopic as opposed to intravesical ${ }^{5}$. In 
females, $95 \%$ are associated with a duplex system while in males $66 \%$ are associated with a single system. ${ }^{1}$ Bilateral ureteroceles or those associated with contralateral duplicity occur in $15 \%$ of cases. ${ }^{6}$

The aetiology is largely speculative. Chwalla ${ }^{1}$ suggested that ureteroceles have an obstructive aetiology due to a delayed and incomplete reabsorption of the membrane that separates the ureteral bud from the mesophrenic duct in the embryo. Tanagho ${ }^{7}$ hypothesized that the distal ureteral segment, which is incorporated later into the developing urogenital sinus, may be acted on by the same factors that cause the expansion of the urogenital sinus to form the bladder, together with a delay in establishing the lumen of the ureteral bud.

The diagnostic work up relies on the use of ultrasound, a cystourethrogram, and a renal isotope scan. Intravenous urography was the most important diagnostic step in the past. Nowadays the progress of ultrasonography and of nuclear medicine imaging has made this examination obsolete in most cases, although when the anatomy is confused, intravenous urography may still play a role. ${ }^{1}$

If the renal parenchyma associated with the ureterocele retains some function, which most commonly occurs in a single system, a characteristic cobra head or spring onion deformity of the intravesical ureter is produced, due to opacified urine in the ureterocele being surrounded by a radiolucent halo that represents the wall of the ureter. More commonly, when the ureterocele is associated with upper pole of a duplex kidney, function is absent or minimal in $90 \%$ of cases; therefore, the radiographic signs are mainly negative, reflecting the displacement of the lower pole renal unit by the hydronephrotic upper pole ureter ${ }^{1}$. The lower pole pelvis is often laterally and downwardly displaced, producing the characteristic drooping lily image. The number of calices is reduced and the upper calices are missing.

Ultrasound of the urinary tract is the first investigation to be performed. It generally depicts very clearly the ureterocele as a sonolucent round image that sits on the bladder base and occupies a portion of the bladder. One or more dilated ureters can be seen behind the bladder. It also gives valuable information on the presence of unilateral or bilateral renal duplicity and on dilatation of the collecting systems.

A voiding cystourethrogram is an essential part of an ureterocele evaluation. It may reveal vesicoureteral reflux in the lower pole ureter $(50 \%)$ or in the contralateral ureter $(25 \%){ }^{4}$

The function of the pole or of the kidney associated with the ureterocele is best assessed by a 99mtechnetium renal scan that shows and quantifies the amount of functioning renal tissue. ${ }^{1}$

In conclusion, the imaging diagnosis of ureterocele is relatively easy and straight- forward and should be sought in any young patient with hydronephrosis.

\section{References}

1. Merlini E, Chiesa PL. Obstructive ureterocele-an ongoing challenge. World J Urol 2004 June ; 22: 107-14.

2. Glassberg KI, Braren V, Duckett JW et al. Suggested terminology for duplex systems, ectopic ureters and ureteroceles. Reports of the Committee on Terminology, Nomenclature and Classification. American Academy of Paediatrics. J Urol 1984; 132:1153-4.

3. Uson AC, Lattimer JK, Melicow MM. Ureteroceles in infants and children: a report based on 44 cases. Paediatrics 1961; 27:971-76. 
P. K. Chhetri et al, Ureterocele - A case report

4. Shokeir AA, Nijman RJ. Ureterocele: an ongoing challenge in infancy and childhood. BJU Int 2002 Nov; 90(8):777-83.

5. Coplen D, Duckett JW. The modern approach to ureteroceles. J Urol 1995; 153:69.
6. Gonzales ETJr. Anomalies of renal pelvis and ureter. In: Kelalis P, King LR, Belman AB (eds) Clinical pediatric urology, 3 rd edn. W.B. Saunders, Philadelphia, pp 53179.

7. Tanagho EA. Embryologic basis for lower ureteral anomalies: an hypothesis. Urology 1976; 48:451-64. 